\title{
Mongolia Wind Resource Assessment Project
}

D. Elliott, National Renewable Energy Laboratory

B. Chadraa, Scientific, Production, and Trade Corporation for Renewable Energy

L. Natsagdorj, Institute of Meteorology and Hydrology

Presented at ENREN'98 Ulaanbaatar, Mongolia September 7-10, 1998

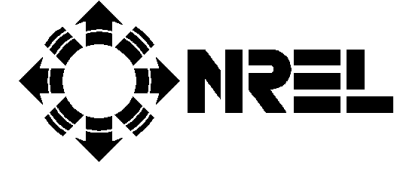

National Renewable Energy Laboratory 1617 Cole Boulevard Golden, Colorado 80401-3393

A national laboratory of the U.S. Department of Energy Managed by Midwest Research Institute for the U.S. Department of Energy under contract No. DE-AC36-83CH10093

Work performed under task number WF7C0201 


\section{NOTICE}

This report was prepared as an account of work sponsored by an agency of the United States government. Neither the United States government nor any agency thereof, nor any of their employees, makes any warranty, express or implied, or assumes any legal liability or responsibility for the accuracy, completeness, or usefulness of any information, apparatus, product, or process disclosed, or represents that its use would not infringe privately owned rights. Reference herein to any specific commercialproduct, process, or service by trade name, trademark, manufacturer, or otherwise does not necessarily constitute or imply its endorsement, recommendation, or favoring by the United States government or any agency thereof. The views and opinions of authord expressed herein do not necessarily state or reflect those of the United States government or any agency thereof.

Available to DOE and DOE contractors from:

Office of Scientific and Technical Information (OSTI)

P.O. Box 62

Oak Ridge, TN 37831

Prices available by calling (423) 576-8401

Available to the public from:

National Technical Information Service (NTIS)

U.S. Department of Commerce

5285 Port Royal Road

Springfield, VA 22161

(703) 487-4650 


\title{
MONGOLIA WIND RESOURCE ASSESSMENT PROJECT
}

\author{
D. Elliott*, M. Legden**, L. Natsagdorj*** \\ *National Renewable Energy Laboratory, Golden, Colorado, U.S.A. \\ **Scientific, Production, and Trade Corporation for Renewable Energy, Ulaanbaatar, Mongolia \\ ***Institute of Meteorology and Hydrology, Ulaanbaatar, Mongolia \\ e-mail: dennis_elliott@nrel.gov
}

\begin{abstract}
The development of detailed, regional wind-resource assessment maps and reliable estimates of other pertinent wind resource characteristics (e.g., seasonal, diurnal, and directional) is an important step in planning and accelerating the deployment of wind energy systems. This paper summarizes the approach and methods being used to conduct a wind energy resource assessment of Mongolia. The primary goals of this project are to develop a comprehensive wind energy resource atlas of Mongolia and to establish a wind measurement program in specific regions of Mongolia to identify prospective sites for wind energy projects and to help validate some of the wind resource estimates. The Mongolian wind resource atlas will include detailed, computerized wind power maps and other valuable wind resource characteristic information for the different regions of Mongolia.
\end{abstract}

\section{Introduction}

The U.S. Agency for International Development and the U.S. Department of Energy are sponsoring a program to help accelerate the use of wind energy technology in Mongolia. A key component of this program is a wind resource assessment project that will define the level of wind resource present across the different regions of Mongolia. The U.S. National Renewable Energy Laboratory (NREL) has the lead responsibility to conduct the wind resource assessment project. The Mongolian organizations participating in this project are the Scientific, Production, and Trade Corporation for Renewable Energy (REC) and the Institute of Meteorology and Hydrology (IMH).

The primary goals of this project are (1) to develop a wind energy resource atlas that depicts the estimated distribution of the wind resource in Mongolia, and (2) to establish a wind measurement program to identify prospective sites for wind energy projects and help validate some of the wind 
resource estimates. The atlas will include estimates of wind speeds and wind power densities on annual and monthly bases, prevailing wind directions, frequency distributions of wind speed (or Weibull k shape parameter), and diurnal and interannual variability of the wind characteristics.

IMH, who collects and archives the meteorological data in Mongolia, is responsible for preparing various types of specific meteorological data for use in the project and will be assisting NREL in the interpretation and analysis of these data. NREL is also using meteorological data obtained from other sources, such as surface and upper-air data transmitted via the Global Telecommunications System network (GTS) of the World Meteorological Organization. REC is primarily responsible for coordinating the wind monitoring activities in Mongolia, including identification of initial sites, installation of the measurement systems, and collection of the data. All the wind measurement equipment for the project is being provided by NREL.

The project began in October 1997. The wind resource atlas is scheduled for completion in October 1999. The wind monitoring activities may continue for an additional year after the completion of the atlas.

\section{Project Activities - Wind Mapping and Atlas Development}

Creation of the wind resource atlas will be accomplished by three primary project activities: (1) collection of existing data and information required for the study, (2) processing and analysis of the data to evaluate and characterize the wind resource, and (3) development of the wind resource maps and preparation of the atlas.

\subsection{Data Collection}

NREL has acquired, as part of its global database, considerable meteorological data from U.S. sources for areas in and near Mongolia. These include surface observations from the period 1973-1996 for stations that transmitted data through the GTS; upper-air observations from the period 1973-1997; and gridded upper-air statistics from the period 1980-1991. IMH has provided a list of all surface and upper-air stations in Mongolia, including periods of wind data collection at each station, observation times, heights of measurement equipment, and other important information useful to the study.

IMH has digitized records of wind speed and direction for over 200 surface locations in Mongolia, including data from both primary and secondary (post) stations. Primary station data are available eight times per day. Post station data are typically available three times per day or in monthly distribution form. IMH has provided NREL with monthly wind speed summaries for 70 primary stations and 157 post stations. NREL has selected some of the stations that appear to have moderate-to-good wind resource, and IMH will provide the detailed observation data for these stations.

IMH archives upper-air meteorological data from 14 locations in Mongolia, but these data have not been digitized. Upper-air observations are available two times per day. Eight of these stations use radiosondes (instrumented weather balloons) to measure upper-air parameters (including temperature and pressure), while others use pilot balloons to estimate only wind speed and direction. NREL's digital upper-air database includes data from the 8 radiosonde stations. Pilotballoon data will be used if IMH can provide these data in digital form. 
Digital terrain and geographic data are essential for use with the computerized mapping software at NREL to facilitate the interpretation of the wind and other meteorological data and to produce the computerized wind resource maps. NREL has, as part of its global terrain and geographic database, the Digital Chart of the World (1:1,000,000 scale maps) and 1-km average elevation data for Mongolia.

\subsection{Data Processing and Analysis}

The reliability of the meteorological input data is the most important factor in creating an accurate wind resource map. A recent NREL paper [1] describes the integration, analysis, and evaluation of different meteorological data sets for use in wind resource assessment. Known problems associated with wind observations taken at many meteorological stations include a lack of information on anemometer exposure, hardware, maintenance history, and observational procedures. An analysis of the meteorological data is performed using techniques developed by NREL specifically for wind resource analysis. A comprehensive data processing package is used to convert the surface and upper-air data to statistical summaries of the wind characteristics. The summaries of the surface station data include, where possible: the interannual variability of wind speed and wind power, the average wind speed and power on a monthly basis, the diurnal distribution of the wind resource, and the mean wind speed and frequency by direction sector. The upper-air meteorological data are processed and analyzed to evaluate the free-air wind characteristics at low levels in the atmosphere and to estimate the vertical distribution of the wind resource. This is useful in estimating the wind resource on elevated terrain features and for estimating the wind resource at exposed locations in areas without reliable surface wind observations.

Site-specific products are screened for consistency and reasonableness. For example, the interannual wind speeds are evaluated to identify obvious trends in the data, or periods of questionable data. Only representative data periods are selected from the entire period for use in the assessment. The summarized products are also cross-referenced against each other to select sites which apparently have the best exposure and to develop an understanding of the wind characteristics throughout the region. This is important due to the variable quality of the data, and the lack of documentation of the anemometer exposure and history. The goal of the data analysis and screening process is to develop a conceptual model of the physical mechanisms, both regional and local in scale, that influence the wind flow.

\subsection{Development of Wind Maps and Atlas}

An automated wind resource mapping system recently developed at NREL will be used to generate the wind resource maps for the different regions of Mongolia. This mapping system has replaced the manual analysis employed in previous mapping efforts conducted in the 1980's and early 1990's. The automated system was developed with the following two primary goals in mind: (1) to produce a more consistent and detailed analysis of the wind resource, particularly in areas of complex terrain; and (2) to generate high-quality map products on a timely basis.

The mapping system uses computerized mapping software known as Geographical Information System (GIS). The main GIS software is ARC/INFO a powerful and complex package featuring a large number of routines for scientific analysis. None of the ARC/INFO analysis routines is specifically designed for wind resource assessment work; therefore, NREL's mapping technique 
requires extensive programming in $\mathrm{ARC} / \mathrm{INFO}$ in order to create combinations of scientific routines that mimic direct wind resource assessment methods.

The wind mapping system is organized into three main components: the input data, the wind power calculations, and output section that produces the final wind resource map. A description and application of NREL's wind mapping system in developing regional-scale wind resource maps can be found in recent publications [2,3]. The two primary inputs to the mapping system are gridded terrain data with $1 \mathrm{~km}^{2}$ resolution and formatted meteorological data. The wind power density, rather than the wind speed, is used in the final analysis of the wind resource, since it provides a truer indication of the wind resource potential. A wind resource assessment handbook recently published by NREL [4] includes methods to compute wind power density and adjust the wind power to different heights above ground. The final meteorological inputs, following the data screening process, are vertical wind power profiles and wind power roses (which specify the percentage of total power from the wind by direction sector). These inputs determine the base wind power density of each grid cell. The GIS is used to adjust the base wind power density value. The factors that have the greatest influence on the adjustment for a particular grid cell are the topography in the vicinity of a grid cell and a combination of the absolute and relative elevation of the grid cell. The primary output of the mapping system is a color-coded map of the estimated wind power, and equivalent wind speed, for each individual grid cell. The maps are designed to highlight areas that possess a favorable wind resource and where wind energy projects are likely to be feasible.

For Mongolia, it is advantageous to divide the country into several different regions in order to generate the wind resource maps. A composite for the whole country will be generated from a combination of the regional maps. Besides the annual average wind resource maps, the atlas will include information on the monthly and diurnal variability of wind resource, and wind direction characteristics for the major resource areas. The wind atlas will be a valuable document for use in identifying prospective areas for wind energy applications in Mongolia. However, because most of the wind resource estimates are preliminary, it is recommended that wind monitoring sites be installed in areas where wind energy applications may be considered.

\section{Project Activities - Wind Measurement and Data Analysis}

REC, IMH, and NREL are cooperating on a project to monitor the wind resource in specific areas of Mongolia. The data collected in this project will be useful to quantify the wind resource characteristics at specific sites where wind energy projects may be considered and to help validate some of the wind resource estimates in the mapping project. NREL has supplied the project with 12 monitoring systems, which REC will install in three regions of southeast Mongolia: Sukhbaatar, Dornogovi, and Omnogovi. REC staff will perform the system installation, data collection and initial analysis tasks. All data will be sent to NREL for further analysis and integration into the assessment project. IMH will also receive the data and assist with the interpretation of the site data and comparison to wind data collected at meteorological stations in the regions.

NREL conducted a training course in Ulaanbaatar from late June to early July 1998. This training course covered the fundamentals for conducting a successful wind monitoring program. These fundamentals are described in NREL's wind resource assessment handbook [4], which served as the handbook for the training course. The training course included procedures for the 
siting and installation of wind monitoring systems and the collection, processing, and analysis of the data.

\subsection{Site Selection}

Four sites within each region will be selected by REC for the installation of the wind monitoring systems. One site in each region will be designated as the permanent site, which will not be moved during the term of the project. The other three monitoring systems in that region can be moved during the project, after sufficient data have been collected to adequately evaluate the wind resource potential. The data from the permanent site will serve as a reference, allowing comparisons between different sites in different years or periods.

Each site will be assigned a unique site number, and its location will be well-documented. Latitude and longitude will be accurately determined with a Global Positioning System receiver, and a complete photographic record of each site will be made.

\subsection{Schedule}

In July to August of 1998, REC traveled to each region to select the sites and install the monitoring systems. In the first three months after installation of the systems, REC will visit each site on a monthly basis to collect the data and inspect the system and data for any problems. During the rest of the project, REC will visit each site at least every three months to collect the data and inspect the system. Periodically, new sites may be identified for re-location of some of the monitoring systems. As the wind mapping project progresses, NREL will offer guidance to REC to help with the identification of new areas for possible wind monitoring.

\subsection{Monitoring Systems}

NREL has supplied 12 Wind Explorer/Tall Tower monitoring systems from NRG Systems, Inc. (Hinesburg, Vermont, U.S.A.) for this project. Each system consists of a 20-m tubular tower (89-mm diameter), a Wind Explorer data logger, an anemometer, and a wind direction vane. The Wind Explorer is capable of recording three data channels at 10-minute intervals for more than six months. In this project, 10-minute averages of wind speed and wind direction measured at a height of 20 meters will be recorded. The maximum interval between visits will be three months. Data are stored on removable DataPlugs that contain 128 kilobytes of non-volatile memory. The DataPlugs will be carried back to the REC offices where they will be read and the data stored on the computer. Copies of all data files will be sent to NREL by electronic mail.

\subsection{Data Analysis}

Initial data analysis (i.e., computation of average wind speeds, wind roses, and quality control) will be performed by REC using the MicroSite program from NRG Systems, Inc. All raw data will also be provided to IMH and NREL. Detailed analysis of the data and integration into the assessment project will be performed by NREL. IMH will assist in the interpretation of the data and comparisons to other measurement sites and meteorological stations in the region. IMH will also assist in evaluating how representative the short-term measurement data is of the long-term average and advise on recommendations for adjustment to the short-term averages. 


\section{Summary}

The wind resource atlas of Mongolia will be a valuable document for evaluating the wind energy potential in Mongolia and for facilitating the identification of prospective areas where wind energy projects may be viable. The atlas will contain high resolution wind resource maps for the different regions of Mongolia and provide information on other important wind characteristics (i.e., the monthly and diurnal variability of the wind resource, frequency distribution of wind speed, and wind direction frequency). The wind resource maps will be produced at NREL using advanced analysis techniques and a new automated wind resource mapping system.

The complementary wind measurement activity in Mongolia will gather data needed to accurately quantify the wind resource potential at specific sites where wind energy projects may be considered, in addition to providing data useful to validate and refine the resource estimates produced by NREL's wind mapping system.

The contributions of the participating Mongolian organizations, IMH and REC, to this project will help to achieve a considerably better wind resource assessment than would be possible otherwise. The additional meteorological data provided by IMH and their assistance with the interpretation of these data is beneficial to developing more reliable and accurate meteorological inputs for the automated mapping system. The efforts by REC to operate and maintain the wind measurement sites will provide data needed to accurately quantify the wind resource potential in specific areas and to validate some of the mapping results.

\section{References}

[1] Schwartz, M.N. and D.L. Elliott: "The Integration of Climatic Data Sets for Wind Resource Assessment", In: Proceedings of the $10^{\text {th }}$ Conference on Applied Climatology, American Meteorological Society, Boston, 1997.

[2] Elliott, D.L. and M.N. Schwartz: "Recent Wind Resource Characterization Activities at the National Renewable Energy Laboratory", In: Windpower '97 Proceedings, American Wind Energy Association, Washington, D.C., 1997.

[3] Elliott, D.L. and M.N. Schwartz: "Validation of Regional Wind Resource Predictions in the Northern Great Plains", In: Windpower '98 Proceedings, American Wind Energy Association, Washington, D.C., 1998.

[4] AWS Scientific, Inc.: Wind Resource Assessment Handbook, NREL/SR-440-22223, National Renewable Energy Laboratory, Golden, Colorado, 1997. 